\title{
Auspicious Patterns of Dragon and Phoenix in Logo Design
}

\author{
Liang Wei \\ School of art and design, Lanzhou Jiaotong University, Lanzhou, Gansu 730070
}

Keywords: dragon; phoenix; pattern; logo

\begin{abstract}
This paper studies auspicious patterns of the dragon and phoenix in modern logo design, analyzes the image and meaning of dragon and phoenix auspicious design, as well as the specific application in logo. As auspicious patterns play an important role in the modern logo design, it is important to fully explore the beneficial elements in the Chinese traditional auspicious patterns and creatively combine the cultural essence of our nation with this nation the modern logo design language to pioneer a new way of logo design.
\end{abstract}

\section{Introduction}

Chinese traditional auspicious patterns are rich in connotation, and have long history and strong national characteristics. As a typical representative of Chinese traditional culture, it combines the art of painting and the art of language, and is Chinese the most traditional visual art resource. In the background of advocating original design today, it is very important to discover and construct a design language with the characteristics of the nation. The study of Chinese traditional auspicious patterns is a way to explore this design language. For a nation with longand profound tradition culture, it will be the source of inspiration and wisdom for "Chinese Design".

\section{Dragon and Phoenix Auspicious Patterns}

Chinese auspicious patterns were design pattern that were created by people for the sake of the traditional mentality of seeking good fortune and avoiding evil, enriched and passed down from generation to generation after a long period of historical screening, with the implied meaning of happy life and good luck ${ }^{[1]}$. Auspicious patterns have already existed in the Shang and Zhou dynasties in China, and developed in Tang and Song dynasties. During the Ming and Qing dynasties, it almost reached the point where the patterns were bound to have auspicious meaning. With the continuous development. Auspicious patterns have extremely rich connotations today, and have been used in all aspects of life. "auspicious" has always been the state of life that the Chinese people yearn for. The emergence of traditional auspicious patterns is deeply rooted in the life of the people, and expresses the most desired living conditions of the people. Based on this national culture, combining traditional auspicious patterns with modern design can not only fully display the unique charm of traditional culture, but also enrich the connotations of design works, make the works full of Chinese characteristics and arouse people's emotional resonance.

"Dragon" and "phoenix", as totems of the Chinese nation, has the supreme position in the hearts of Chinese people. "Dragon" is characterized by unpredictable mystery, and symbolizes authority, tall, brave, auspicious and so on, the ancient emperors compared themselves to the "real dragon and the son of heaven"; Among the people, the Chinese people all over the world call themselves "descendants of the dragon"; We generally compare people with talent and status as "dragon and Phoenix", the industry leaders are called "industry leaders"; "hoping the next generation become dragon" means parents wish their offspring can have a bright future. In addition, dragon boat race on "Dragon Boat Festival" and "dragon dance on Spring Festival" are folk activities in which people pray for good weather, good grain and celebrate the festival. "Phoenix" as a god bird, with gorgeous color and noble quality, symbolizes good luck, peace and so on. According to legend, when it comes, it can bring happiness and health to the world. The traditional patterns of phoenix, such as "auspicious dragon and phoenix", "phoenix flies towards sun", "birds paying homage to the 
phoenix", all express a desire for a beautiful and happy life and peace in the world. The patterns of dragon and Phoenix are highly decorative, can be short and long, can be rounded, square and curled at will, suitable for various forms, and become one of the most oriental decorative patterns in the decorative pattern ${ }^{[2]}$. The traditional pattern is a visual symbol which has been highly summarized and refined, which condenses the wisdom of the Chinese nation for thousands of years. As an important part of Chinese traditional culture, it needs to be inherited and spread constantly.

Logo design is a kind of visual language, made of designed patterns and words to convey information in a symbolic language and a particular shape or pattern, in order to express a particular meaning or thing ${ }^{[3]}$. The combination of the beautiful meaning of dragon and phoenix auspicious design and logo design is bound to inject new vitality into modern logo design. Logo design should be based on national traditional culture and guided by modern design idea and form, integrate the world's advanced culture and excellent Chinese traditional Culture, pay attention to embody our nation's psychological characteristics and aesthetic sentiment in inheritance and innovation ${ }^{[4]}$. Only then can it be widely used in all fields of economy and society, and be recognized by the public, thus realizing its social value.

\section{Logo in the shape of dragon}

Since ancient times, “dragon” has been a symbol of courage, authority and nobility ${ }^{[5]}$. It is also a sign of luck and success. This model form has been applied to many logo designs to express good symbolic significance.

SINO JET is a brand new brand created by Hong Kong-based SINO JET and Beijing-based Big White Bear Commercial Aviation. The logo (figure 1) was inspired by the dragon and Phoenix, symbolizing the megamerger of two commercial airlines like the perfect combination of dragon and Phoenix. The dragon head and Phoenix in the figure crown upswing, with a strong aviation industry characteristics, showing the state of harmony of dragon and Phoenix, full of vigorous development momentum. The ancient totem and the English alphabet combination, implies the organic fusion of Chinese culture and world culture. It represents the enterprise actively pursues excellence and the pioneer spirit. At the same time, prosperous and promising prospects is also showed by the logo. The lines pf this logo is smooth, with a strong sense of beauty and visual impact.

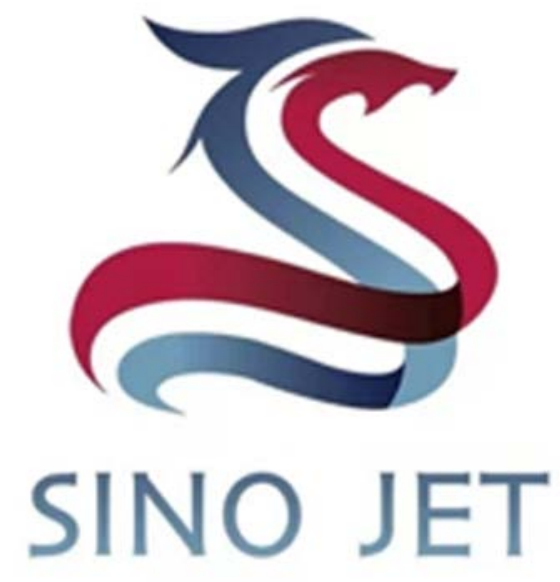

Figure.1 “SINO JET” logo

In 1971, Hongshan cultural jade dragon was unearthed at the Hongshan cultural site in Chifeng city. The jade dragon was the source of the Chinese dragon, which was in about5000 years ago. The jade dragon was regarded as the symbol of Hongshan culture by archaeological circle ${ }^{[6]}$. It is called "the first Dragon of Ancient China". The mark of Shenzhen Shangchen decoration design Engineering Co. Ltd. (Figure 2), takes concise “jade dragon” as the main body. The simplified dragon head, "Chen" first letter " $C$ ”, combining with industry house which presents the industry, means people-oriented company attitude, excellent service quality, and present the notion of 
providing customers with the most satisfactory living environment. At the same time, "Dragon" is the ancient mythology of the Eastern God, as well as the noble, momentum and emperor symbol, with this brand image, signifying the magnanimity of the enterprise, becomes a new benchmark in the industry. The whole symbol contains profound culture and industry characteristics.

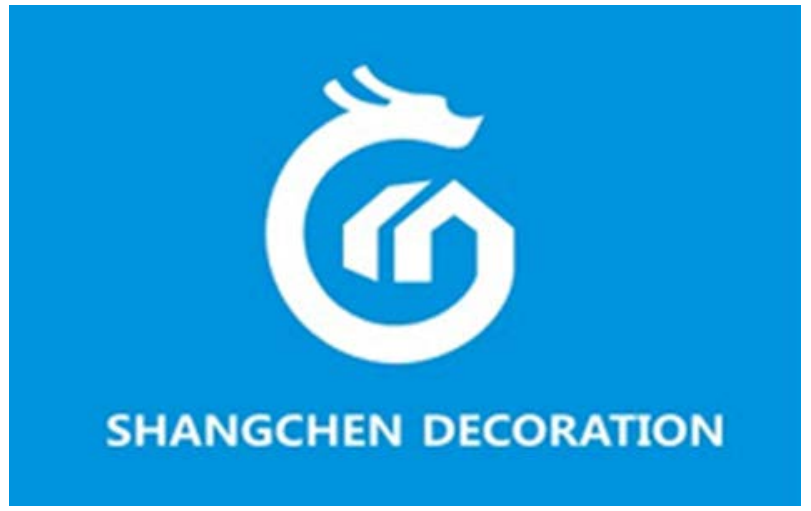

Figure .2 “Shenzhen Shangchen decoration design Engineering Co. Ltd”logo

The Chinese lunar exploration project, also known as the Chang'e Project, is symbolized by Shanghai designer Gu Yongjiang's “above the Moon' (figure 3), the famous flying white brushwork in traditional Chinese painting, with a lifelike image of a giant dragon. The logo presents strong strength and and the shape of Chinese character- "Yue". The logo depicts a moon outline, a pair of small footprint, a symbol of China lunar exploration project "China dream". The head of the dragon, is a symbol of the thriving aerospace industry Chinese, the perseverance to explore the mysteries of the universe. The concise dragon bold image makes logo design novel and unique, easy to remember. It shows Chinese spirit of exploring Lunar Lunar, conveys industrious and courageous faith of Chinese descendant, stimulates the innovative, exploration and science spirit of our nation [7].

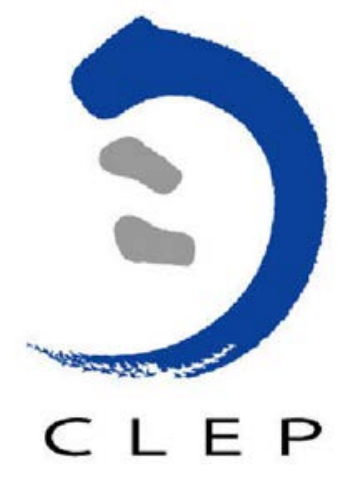

Figure. 3 “Chinese Lunar Exploration Program” logo

\section{The Logo in shape of phoenix}

Phoenix is viewed as auspicious bird by people, known as the king of birds, which is a symbol of peace, happiness and auspicious omen ${ }^{[8]}$. The pattern- "auspicious dragon and phoenix" is an auspicious pattern with Chinese characteristics.

For example, Wuxi city emblem (figure 4), with the "jade phoenix" as the main body and the combination of landscape and city flowers (plum flowers), constitutes a complete, satisfactory cultural symbol. The overall shape is full and round. As a precious cultural relic of Wuxi, "jade phoenix" is elegant in shape and moving in posture. It shows the intelligence of Wuxi people and the prosperity of Wuxi City. The water pattern represents that the Yangtze River and Taihu Lake. Ancient canal, the two springs in Wuxi, echoing the mountain shape, and interprets that Wuxi is 
charaterized by beautiful scenery, is a livable city, as well as reflects the landscape Wuxi and the prosperity the jade phoenix brings to Wuxi.

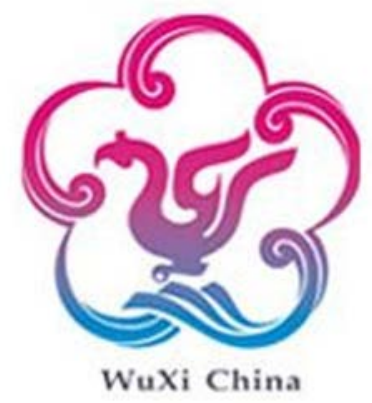

Figure. 4 Wuxi city emblem

Another example is the logo of Beijing Rural Commercial Bank (Figure. 5), which is composed of Phoenix and Taiji. The overall style is simple, elegant and modern, which fully reflects the perfect combination of tradition and modern.

The upward phoenix head means that Beijing Agricultural and Commercial Bank has great goals and ambitions to construct modern joint-stock commercial banks. Surrounded by phoenix tail, it means Beijing Agricultural and Commercial Bank sticks to customers' needs and customer-oriented service concept. The overall shape is full, soft, stable, showing the proactive, enthusiastic service of Beijing Agricultural and Commercial Bank and the characteristics of steady operation. The logo details are dynamic, with obvious national characteristics, both in line with the aesthetic views of the public and the international design trend.



\section{BEIJING RURAL COMMERCIAL BANK}

Figure. 5 “Beijing Rural Commercial Bank”logo

China Youth Travel holding Co., Ltd. is a joint stock limited company established through the process of recruitment and preparation, with the China Youth Tour Society as the main sponsor. It is the first A-share listed companies and Beijing's first 5A-class travel agencies.

China Youth Travel logo (figure 6), is composed of the earth, the sun, Phoenix three design elements. The earth symbolizes the broad and unrestrained service field and growing space of China Youth Travel Tour; the sun, represents the vision of its bright future; Phoenix, is noble and beautiful, signifies its leading position of in the industry.

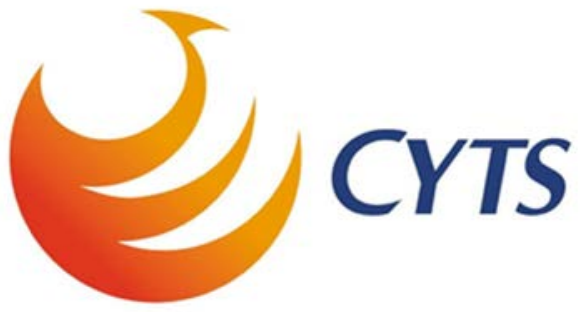

Figure. 6 “China Youth Travel holding Co., Ltd”logo 


\section{Conclusions}

As an important part of Chinese traditional culture, auspicious pattern is the treasure of Chinese national culture and wisdom. It is not only the symbol and expression of Chinese long history, but also an inexhaustible design source of modern art ${ }^{[9]}$. We should make use of the past for the present, inherit and carry forward its unique symbolic significance and rich connotation. At the same time, we should not blindly adhere to bringism, and are supposed to sort out the good from the bad, and draw inspiration and nutrition from traditional auspicious patterns.

The cultural art should attach importance to innovation. The traditional auspicious decoration art should combine with the modern design language, and takes its "shape" as its "meaning "on the basis of understanding the works of the previous person, so as to present the "spirit" of the art ${ }^{\text {[10] }}$ and grant the Chinese design new characteristics of the times, exuberant vitality and deeper concept, and meets the aesthetic needs of the present world. Only in this way, the design of our country can spread abroad, better be connected with the advanced design of the world, fully show Chinese profound culture, and then enhance Chinese cultural confidence.

\section{References}

[1] Wang Mei-lin. Innovative Application of Traditional Auspicious Patterns in Modern Design [J]. Packaging Engineering, 2011, 32 (14):8.

[2] Zhang Li-zhu. Chinese traditional decorative elements -- dragon and Phoenix [J]. Journal of Inner Mongolia Normal University (Philosophy and Social Science), 2006, 35(05):462.

[3] Men De-lai. Modern logo design creativity and performance [M]. Xi'an: Xi'an Jiao Tong University press, 2003.

[4] Ji Xiang-hong. Logo and corporate image design [M]. Beijing: Tsinghua University press, 2011.

[5] Zheng Jun, WEI Feng. Chinese auspicious pattern design art [M]. Beijing: People's Fine Arts Publishing House, 2010.

[6] Lu Xiao-yun. Cultural Connotation and Artic Presentation in Symbols of Dragons and Phoenixes [J]. Journal of Nantong University (Social Sciences Edition), 2012, 28 (01):83.

[7] Pu Li-jie. The application of auspicious patterns in modern logo design [J]. Intelligence, 2009 (09):242.

[8] Ma Ze-qun. History of the Dragon and Phoenix Pattern [J]. Journal of Chengdu Textile College, 2008, 25 (01):76.

[9] Du Shu-xian, Wang Hui, Wang Yan-hui. The inheritance and development of traditional auspicious patterns in modern design [J]. Art Education, 2010 (08):140.

[10] Ma Jun. The National Culture Connotation of Auspicious Patterns [J]. Hundred Schools in Arts, 2010 (07):161.

Author profile: liang wei (1985-), male, gansu cheng county man, master, lecturer of school of art design, lanzhou jiaotong university, main research direction is visual communication design.

Address: no.105, Lanzhou Jiaotong University, no. 88, anning road, anning district, lanzhou city, gansu province, 730070 . 